\section{Commentary: It is a matter of choice}

\author{
James E. O’Brien, Jr, MD
}

Patients with tetralogy of Fallot (TOF) and major aortopulmonary collaterals (MAPCAs) remain among the most challenging patients we encounter as congenital cardiac surgeons. In this issue of the Journal, Ma and colleagues ${ }^{1}$ add to the impressive body of work coming from the program at Lucille Packard in treating patients with TOF and MAPCAs. In their report, they present a review of patients who had undergone surgery for this defect at outside institutions before referral to their center. ${ }^{1}$ The success of the Stanford program has resulted in the referral of a substantial number of patients to their program for consultation and ongoing management. The cohort of patients referred from the outside represents a sizable portion $(35 \%)$ of their total experience during the 18 years of the study period. It is an impressive cohort with very successful results. But what does this mean for us mere mortals trying to learn from their experience?

This group has previously presented their outcomesoutstanding outcomes-for unifocalization in patients with TOF and MAPCAs and shown that previous surgery was not associated with a significant difference in outcomes. ${ }^{2}$ The cohort presented in their present report is heterogeneous and an inherent selection bias is present-all the patients with previous surgery were evaluated by the experienced group at Stanford and found to be candidates for unifocalization. ${ }^{1}$ A conclusion could easily be drawn that the success of these reoperative surgeries is contingent on a successful selection process. As such, the ability of other centers to incorporate the results of the study by $\mathrm{Ma}$ and colleagues ${ }^{1}$ into their practices remains limited.

One could argue that it is important to demonstrate that the selection process worked as designed and that the

\footnotetext{
From the Division of Cardiothoracic Surgery, Ward Family Heart Center, Children's Mercy Hospital, University of Missouri School of Medicine - Kansas City, Kansas City, Mo.

Disclosures: The author reported no conflicts of interest.

The Journal policy requires editors and reviewers to disclose conflicts of interest and to decline handling or reviewing manuscripts for which they may have a conflict of interest. The editors and reviewers of this article have no conflicts of interest.

Received for publication April 30, 2020; revisions received April 30, 2020; accepted for publication April 30, 2020; available ahead of print May 15, 2020.

Address for reprints: James E. O'Brien, Jr, MD, Division of Cardiothoracic Surgery, Ward Family Heart Center, Children's Mercy Hospital, Kansas City, MO 64108 (E-mail: jobrien@cmh.edu).

J Thorac Cardiovasc Surg 2020;160:1281

$0022-5223 / \$ 36.00$

Copyright (C) 2020 by The American Association for Thoracic Surgery

https://doi.org/10.1016/j.jtcvs.2020.04.158
}

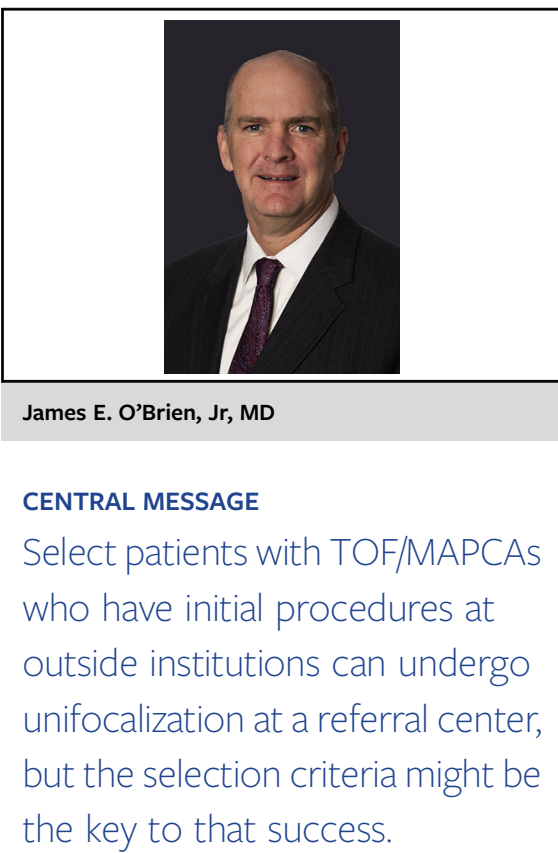

selection of appropriate candidates did indeed lead to successful outcomes. A further elucidation of such a selection process used to determine eligibility would be of interest to other programs. Experienced clinical judgment certainly would play an important role in the selection process. However, there most certainly are other factors. The authors state that a small percentage of patients were determined not to be candidates for complete repair because of pulmonary vascular disease and the loss of pulmonary vessels. ${ }^{1}$ However, they also conclude that patients with extensive residual pulmonary disease, including those with occluded central or peripheral branch pulmonary arteries, are not precluded from complete repair. ${ }^{1}$ The identification of objective data used as relative or absolute criteria for selection would be very beneficial and impactful to our field.

The inability to generalize these data to other institutions in no way distracts from the outstanding work performed by the authors, and they deserve congratulations. Their expertise extends to their ability to select appropriate patients. Thus, as with so many things in life, our successes are determined by our choices.

\section{References}

1. Ma M, Zhang Y, Wise-Faberowski L, Lin A, Asija R, Hanley FL, et al Unifocalization and pulmonary artery reconstruction in patients with tetralogy of Fallot and major aortopulmonary collateral arteries who underwent surgery before referral. J Thorac Cardiovasc Surg. 2020;160:1268-80.e1.

2. Bauser-Heaton H, Borquez A, Han B, Ladd M, Asija R, Downey L, et al. Programmatic approach to management of tetralogy of Fallot with major aortopulmonary collateral arteries. Circ Cardiovasc Interv. 2017;10: e004952. 